\title{
The Noradrenergic Innervation and Steroidogenic Activity of Porcine Cystic Ovaries
}

\author{
A. KOZLOWSKA ${ }^{1,2}$, J. WOJTKIEWICZ ${ }^{3}$, M. MAJEWSKI ${ }^{2}$, B. JANA ${ }^{1}$ \\ ${ }^{1}$ Division of Reproductive Biology, Institute of Animal Reproduction and Food Research of the \\ Polish Academy of Sciences, Olsztyn, Poland, ${ }^{2}$ Department of Human Physiology, Faculty of \\ Medical Sciences, University of Warmia and Mazury, Olsztyn, Poland, ${ }^{3}$ Department of Neurology \\ and Neurosurgery, Faculty of Medical Sciences, University of Warmia and Mazury, Olsztyn, \\ Poland
}

Received September 25, 2012

Accepted February 12, 2013

On-line April 16, 2013

\begin{abstract}
Summary
The aim of the present study was to investigate the distribution and density of noradrenergic nerve fibres (NNFs), content of catecholamines (CATs) and steroids in the cystic ovaries of gilts receiving DXM from middle luteal phase. Cystic status of ovaries was induced by i.m. DXM injections on days 7-21 of the estrous cycle. During the same time, gilts in the control group received saline. The ovaries were collected on predicted day 11 of the second studied estrous cycle. The cystic ovaries were supplied by more numerous NNFs than the control gonads. Moreover after DXM injections, the content of CATs and progesterone and androstendione $\left(A_{4}\right)$ in the cystic wall were elevated, while the levels of $A_{4}$, testosterone and estradiol-17 $\beta$ in the cystic fluid were lowered. Our results show that in the porcine cystic ovaries, induced by DXM injections from middle phase of estrous cycle, increased the density of NNFs and level of CATs, and that it was accompanied by changes in the content of steroids. Moreover, this study is a further confirmation that the morphological and functional changes of cystic ovaries are partly dependent on phase of the estrous cycle in which the induction of the ovarian cysts was initiated.
\end{abstract}

\section{Key words}

Ovarian cysts • Noradrenergic innervation • Steroids • Pigs

\section{Corresponding author}

A. Kozłowska, Department of Human Physiology, Faculty of Medical Sciences, University of Warmia and Mazury, Warszawska 30, 10-561 Olsztyn, Poland. E-mail: kozlowska.anna@uwm.edu.pl

\section{Introduction}

Cystic ovarian disease (COD) is one of the most common reproductive disorders in female of farm animals, affecting 6 to $19 \%$ of dairy cattle (Kesler and Garverick 1982) and 2.4-40 \% of sows (for a review see Cech and Dolezel 2007, Szulańczyk-Mencel et al. 2010) which may result in temporary or permanent infertility. Despite extensive investigations, the etiopathogenesis of COD is not completely understood. It is assumed that cystic condition is mainly caused by disturbances in the function of hypothalamic-pituitary-ovarian (HPO) axis leading to impairment of the synthesis, release and storage of various hormones of this functional unit (Silva et al. 2002, Peter 2004). One of the reasons of changes in the HPO axis activity and ovarian cysts formation may be stressors activating of the hypothalamic-pituitaryadrenocortical (HPA) axis. An increase in corticotropinreleasing hormone secretion suppresses the activity of the hypothalamic GnRH pulse generator, leading to a decrease in release of GnRH and LH (Li et al. 2005). Moreover, elevated level of adrenocorticotropic hormone (ACTH) reduces pulsatory LH release from pituitary, stimulates produce and release of glucocorticoids from the adrenal cortex that inhibit the release of GnRH and/or LH and ovarian activity (Turner et al. 2002, Madej et al. 2005). The experimental evidence also strengthen the role of sympathetic innervation in the etiopathogenesis and/or persistence of ovarian cystic condition. Numerous studies, performed under physiological conditions, 
showed that intraovarian sympathetic nerve fibres localized around follicles, corpora lutea (CLs), blood vessels and interstitial gland as well as within ground plexus, participate in regulation of steroidogenesis, follicular development and ovulation (Majewski 1997, Morán et al. 2003, Jana et al. 2007). The effect of stressors in the pathogenesis of polycystic ovary is mediated by sympathetic discharge originating at the paraventcicular nucleus (Fiedler et al. 2006). It was revealed that in the cystic ovaries of humans (Nakamura 1990, Heider et al. 2001), rats (Barria et al. 1993, Lara et al. 2000), gilts (Jana et al. 2005) and cows (Paredes et al. 2011) the sympathetic nerve activity is increased. Moreover, the important role of the nerve fibres in the etiopathogenesis of the ovarian cysts provided the fact that the resection of the ovarian medulla fragment contained the part of nerves supplying the ovary (Nakamura 1990) or laparascopic laser cauterization of this place (Balen and Jacobs 1994) in women with polycystic ovary syndrome (PCOS), in which the hormonal therapy was ineffective, induced ovulation. Similar effect was also observed in rats with PCOS after unilateral sectioning of the superior ovarian nerves (Morales-Ledesma et al. 2010). Furthermore, the hyperactivation of ovarian sympathetic nerves seen in estradiol valerate (EV)-induced polycystic ovaries in rats is related to an overproduction of nerve growth factor (NGF) and its low affinity receptor in the gonads (Lara et al. 2000, Manni et al. 2005).

Our earlier study showed that in the ovaries of gilts, in which COD was induced by i.m. dexamethasone phosphate disodium salt (DXM) injections from 16 of the first studied estrous cycle to day 9 of the second studied cycle, the density of noradrenergic nerve fibres and the content of catecholamines increased, which was accompanied by distinct changes in the steroidogenic activity of the gonads (Jana et al. 2005). It was presented that the morphological and functional changes of cystic ovaries are dependent on both the kind of hormones inducing this pathological state, and also the phase of the estrous cycle, in which administration of this hormone was started (Frautschy and Liptrap 1988, Gee et al. 1991). Also, the content of noradrenaline (NA) in the porcine ovary depends on the phase of the estrous cycle and the period of the pregnancy (Lakomy 1987, 1988). Moreover, the exogenous sex steroids influence the NA amount in the ovaries of immature gilts (Lakomy 1987).

The findings mentioned above and literature data allow to hypothesize that changes in the noradrenergic innervation pattern as well as steroidogenic activity of cystic ovaries, induced by DXM treatment from middle luteal phase of the estrous cycle, will be most probably different from those, found after induction of cyst formation from follicular phase (Jana et al. 2005). Therefore, the aim of the present study was to determine the changes in the noradrenergic innervation pattern and in the content of catecholamines and steroid hormones in the porcine cystic ovaries induced by DXM treatment from middle luteal phase of the estrous cycle.

\section{Methods}

\section{Animals and experimental procedure}

We followed the principles of animal care (NIH publication No. 86-23, revised in 1985) as well as the specific national law on animal protection. The experiment was carried out on 12 crossbred gilts (Large White $\mathrm{x}$ Landrace), aged 7-8 months and weighing 90-100 kg, with two controlled subsequent estrous cycles. Behavioural estrus was detected by using the boar-tester. The animals were then individually housed in stalls, under conditions of natural light and room temperature. They were fed with a commercial grain mixture and tap water ad libitum. The gilts were randomly assigned to one of two groups: control, receiving saline $(\mathrm{CON}, \mathrm{n}=6)$ and DXM-treated (DXM, $\mathrm{n}=6$ ).

In the DXM group, the cystic status of ovaries was induced according to the protocol described earlier by Gee et al. (1991) with following modifications: the gilts in the present study received DXM $(3.3 \mu \mathrm{g} / \mathrm{kg}$ of body weight, in total volume of $6 \mathrm{ml}$; Dexasone ${ }^{\circledR}$, Norbrook Laboratory, Newry, UK) every 12 h, starting on day 7 (day 1 of the study) to day 21 of the first studied estrous cycle (i.e. during 15 consecutive days). During the same period of time, animals of the CON group were injected with $6 \mathrm{ml}$ of saline. The gilts were then slaughtered by electrical shock (ENZ 300 Metalowiec, Bydgoszcz, Poland) and exsanguinated on predicted day 11 of the second studied cycle (i.e. on day 26 of the experiment). The ovaries were immediately dissected out and their weight, volume, measurements as well as the numbers of follicular structures and CLs were estimated. The follicles were divided into two size classes: small (1-3 $\mathrm{mm}$ in diameter) and medium (4-6 $\mathrm{mm}$ in diameter). Follicular structures exceeding $1.0 \mathrm{~cm}$ in diameter were classified as cysts (Nalbandov 1952). The morphological examination of ovaries was described earlier (Kozłowska 
et al. 2009), and it showed that DXM injections on days 7-21 of the estrous cycle caused, comparing to the control group, formation of partly luteinized follicular cysts, a decrease in the number of small follicles and the lack of medium follicles and CLs. Afterwards, blocks of ovarian tissue were processed for further immunochemical studies as follows: they were fixed by immersion in Zamboni's fixative for $30 \mathrm{~min}$, washed in $0.1 \mathrm{M}$ phosphate buffer, stored in $18 \%$ sucrose for several days and then frozen $\left(-80^{\circ} \mathrm{C}\right)$ and stored until sectioning. Follicular fluid was collected and stored at $-21^{\circ} \mathrm{C}$ to determine concentrations of progesterone $\left(\mathrm{P}_{4}\right)$, androstendione $\left(\mathrm{A}_{4}\right)$, testosterone $(\mathrm{T})$, estrone $\left(\mathrm{E}_{1}\right)$ and estradiol-17 $\beta\left(E_{2}\right)$. Next, the cystic and follicular wall as well as CL samples were shock-frozen in liquid nitrogen and then stored at $-80^{\circ} \mathrm{C}$ in order to analyse the contents of the steroid hormones. To estimate the content of catecholamines in follicular and cystic fluid, the samples were collected immediately after excision of the ovary and estimation of above-mentioned parameters (up to $1 \mathrm{~min}$ ) was carried in tubes containing $1 \mathrm{~N} \mathrm{HCl}$ to prevent oxidation and they were later kept on ice. Next, pieces of follicular or cystic wall were dissected out, weighed and, in order to estimate the content of catecholamines, were placed in tubes $\left(4^{\circ} \mathrm{C}\right)$ containing aqueous solution of $0.4 \%$ perchloric acid, $0.1 \%$ EDTA, $0.1 \%$ sodium metabisulfite and $0.01 \%$ ethanol, prepared ex tempore to prevent oxidation of amines and to precipitate proteins. Fluid and tissue samples were stored at $-80{ }^{\circ} \mathrm{C}$ until assayed by high-performance liquid chromatography (HPLC).

\section{Double-labelling immunofluorescence}

Ten- $\mu \mathrm{m}$-thick cryostat (Reichert-Jung, Nußloch, Germany) sections of the ovaries were subjected to routine double-immunofluorescence staining technique to visualise the distribution of noradrenergic population of nerve fibres containing dopamine- $\beta$-hydroxylase $(\mathrm{D} \beta \mathrm{H})$ and/or neuropeptide tyrosine Y (NPY). The sections were air-dried at room temperature (RT) for $45 \mathrm{~min}$ and rinsed (3 $\mathrm{x} 15 \mathrm{~min}$ ) with PBS (phosphate buffered saline, pH 7.4). Next, sections were blocked with a blocking mixture containing $1 \%$ Triton X100, $0.1 \%$ bovine serum albumin, $0.05 \%$ thimerosal, $0.01 \% \mathrm{NaN}_{3}$ and $10 \%$ normal goat serum in $0.01 \mathrm{M}$ phosphate-buffered saline for $1 \mathrm{~h}$ at $\mathrm{RT}$ to reduce non-specific background staining. After a wash, sections were incubated overnight in the humid chamber at RT with a mixture of primary antisera raised in different species and recognizing $\mathrm{D} \beta \mathrm{H}$ (mouse monoclonal, working dilution 1:400; MAB308, Chemicon, USA) and NPY (rabbit polyclonal, working dilution 1:10 000; NA1233-0100, Affinity, UK). Primary antisera were then visualized by a mixture of FITC-conjugated donkey anti-mouse IgGspecific (working dilution 1:400; 715-095-150, Jackson Immunoresearch, USA) and CY3-conjugated donkey anti-rabbit IgG-specific antisera (016-160-084, Jackson Immunoresearch, USA); after the incubation, sections were washed again and then covers were lipped with carbonate-buffered glycerol ( $\mathrm{pH} 8.6)$. The specificity of primary antisera was tested as follows: sections were incubated with antibody that had been preabsorbed with synthetic antigen (10 $\mathrm{gg}$ of antigen per ml diluted antiserum); the primary antibody was omitted from the incubation; either normal rabbit or mouse serum was substituted for the primary antibody.

Double-immunolabelled nerve fibres were analyzed under Olympus BX51 microscope equipped with epi-fluorescence and appropriate filter sets. The distribution and density of intraovarian D $\beta \mathrm{H}-$ and NPYimmunoreactive (IR) nerve fibres were estimated in the surrounding zone of follicles, cysts, CLs, blood vessels, interstitial glands and within the autonomic ground plexus. In order to evaluate differences in the pattern of perifollicular nerve fibres, follicles were, depending on their stage of development, microscopically classified according to Wulff et al. (2002) and Barboni et al. (2004) into following classes: primordial - without granulosa cells, primary - surrounded by a single layer of cuboidal granulosa cells, secondary - with two or more granulosa cell layers without antral cavity, and tertiary - with antrum. Additionally, the tertiary follicles were divided into two size classes: up to $3 \mathrm{~mm}$ (small) and 4-6 mm (medium) in diameter. As mentioned earlier, follicular structures exceeding $1.0 \mathrm{~cm}$ in diameter were classified as cysts (Nalbandov 1952). The D $\beta H$ - and NPY-IR nerve fibres supplying the particular ovarian structures were counted on nine randomly chosen ovarian sections from each gilt, and then the mean ( \pm SEM) numbers of fibres for each group (from fifty-four sections) were calculated.

\section{Catecholamine analyses}

The contents of NA, dopamine (DA) and adrenaline (AA) in the follicular and cystic fluid and wall as well as in the CLs were estimated according to Skipor et al. (2004). Briefly, $25 \mu \mathrm{l}$ of the prepared tissue supernatant and fluids were injected into a $\mathrm{C} 18$ reverse- 
phase column (Hypersil BDS, Thermo Electron Corporation, USA) of HPLC equipped with electrochemical detector TOA ICA-3000 SYSTEM (Tokyo, Japan). The mobile phase consisted of citratesodium phosphate buffer ( $\mathrm{pH} 4.2$ ) containing $0.3 \mathrm{mM}$ octane sulfonate, $0.01 \mathrm{M}$ EDTA, $1.5 \%$ methanol (Merck, Poland) and $1.0 \%$ acetonitrile (Merck, Poland) The flow rate was set at $0.8 \mathrm{ml} / \mathrm{min}$. Separated catecholamines were then detected by a glassy carbon electrode, at the potential of $850 \mathrm{mV}$ vs. $\mathrm{Ag} / \mathrm{AgCl}$ reference electrode. Recovery of the DL-isoproterenol hydrochloride (Sigma, Poland), as an internal standard, was $75 \%$. Final data was corrected for procedural losses.

\section{Hormone analyses}

Extraction of $\mathrm{P}_{4}, \mathrm{~A}_{4}, \mathrm{~T}, \mathrm{E}_{1}$ and $\mathrm{E}_{2}$ from the follicular and cystic wall and the CLs was performed by means of the method described by Tsang et al. (1990). The contents of the studied hormones in the follicular and cystic fluid as well as extracts prepared from the follicular and cystic wall, and also CLs were estimated by the radioimmunoassay procedures and published for $\mathrm{P}_{4}$ and $E_{2}$ by Hotchkiss et al. (1971), for $A_{4}$ and $E_{1}$ by Dziadkowiec et al. (1982a) and for T by Kotwica and Williams (1982). Characteristics of antibodies (obtained from the Institute of Animal Physiology, University of Warmia and Mazury in Olsztyn, Poland) have previously been provided for $\mathrm{P}_{4}$ by Dziadkowiec et al. (1982b) and for the remaining steroids by Szafranska et al. (2002). The sensitivity of the assay for $\mathrm{P}_{4}, \mathrm{~A}_{4}, \mathrm{~T}, \mathrm{E}_{1}$ and $\mathrm{E}_{2}$ was $15,5,2.5,2.5$ and $5 \mathrm{pg} / \mathrm{ml}$, respectively. Intra- and interassay coefficients of variation for $\mathrm{P}_{4}, \mathrm{~A}_{4}, \mathrm{~T}, \mathrm{E}_{1}$ and $\mathrm{E}_{2}$ were 4.5 and $10.6 \%, 6.0$ and $13.4 \%, 7.6$ and $11.9 \%$, 6.5 and $11.8 \%, 7.0$ and $13.8 \%$, respectively. Standards of $\mathrm{P}_{4}, \mathrm{~A}_{4}, \mathrm{~T}, \mathrm{E}_{1}$ and $\mathrm{E}_{2}$ derived from Sigma Chemicon Co, while the $\left[{ }^{3} \mathrm{H}\right]$-labelled $\mathrm{P}_{4}, \mathrm{~A}_{4}, \mathrm{~T}, \mathrm{E}_{1}$ and $\mathrm{E}_{2}$ originated from Amersham plc UK.

\section{Statistical analysis}

To calculate the statistical significance in the mean $( \pm$ SEM) contents of catecholamines and steroid hormones in follicular and cystic fluid and wall as well as the numbers of D $\beta \mathrm{H}$ - and NPY-IR nerve fibres supplying the particular ovarian structures between the CON and DXM groups, one-way analysis of variance (ANOVA) followed by the Bonferroni test was chosen (InStat GraphPad, San Diego, CA). Differences with probability of $\mathrm{P}<0.05$ were considered significant.

\section{Results}

Distribution and density of the noradrenergic nerve fibres in the control and cystic ovaries

In the ovaries of DXM-treated gilts the number of $\mathrm{D} \beta \mathrm{H}$ and NPY- IR nerve fibres, often forming fascicle, around cysts (Fig. 1B) was higher $(\mathrm{P}<0.001)$ than in the vicinity of medium follicles of the CON group (Fig. 1A). Furthermore, in the DXM group an increase in the number of nerve terminals mentioned above was found enclosing the interstitial gland $(\mathrm{P}<0.001$, Fig. $1 \mathrm{H})$ and near cortical $(\mathrm{P}<0.001$, Fig. $1 \mathrm{D}-$ arteries; $\mathrm{P}<0.001$, Fig. $1 \mathrm{~F}-$ veins $)$ and medullar $(\mathrm{P}<0.05$, Fig. $2 \mathrm{D}-$ arteries; $\mathrm{P}<0.001$, Fig. $2 \mathrm{~F}-$ veins) blood vessels. After DXM administration populations of the D $\beta \mathrm{H}$ - and NPY- IR nerve fibres, often forming big fascicles, were greater $(\mathrm{P}<0.001)$ within medullar part of ground plexus (Fig. 2B) than in the CON group (Fig. 2A). In turn, application of DXM did not significantly change the populations of D $\beta H$ and NPY-IR nerve fibres within cortical part of ground plexus and around secondary and small tertiary follicles. Data concerning the distribution and density of noradrenergic nerve fibres are presented in Table 1.

\section{Content of catecholamines in the cystic and follicular fluid}

The NA concentration in the cystic fluid was lower $(\mathrm{P}<0.001)$ as compared to medium follicles of the CON group. The contents of DA and AA in the cystic fluid were below the threshold of detection. After DXM injections the level of NA in the fluid from small follicles was greater $(\mathrm{P}<0.001)$ than in the $\mathrm{CON}$ group. The concentration of DA in fluid from small follicles was similar in the CON and DXM groups. Moreover, the content of AA in the fluid from small follicles in both the CON and DXM groups as well as the levels of DA and $\mathrm{AA}$ in the fluid from medium follicles of the $\mathrm{CON}$ group were below the threshold of detection (Table 2).

Content of catecholamines in the cystic and follicular wall and CLs

The concentrations of DA, NA and AA in the cystic wall were higher $(\mathrm{P}<0.001)$ than in the wall of medium follicles of the $\mathrm{CON}$ group. The greater $(\mathrm{P}<0.001)$ content of NA was revealed also in the wall of small follicles of the DXM group. The amounts of DA and AA in the wall of small follicles were similar in both the CON and DXM groups. In turn, the content of NA in CLs in the CON group was below the threshold of detection (Table 2). 


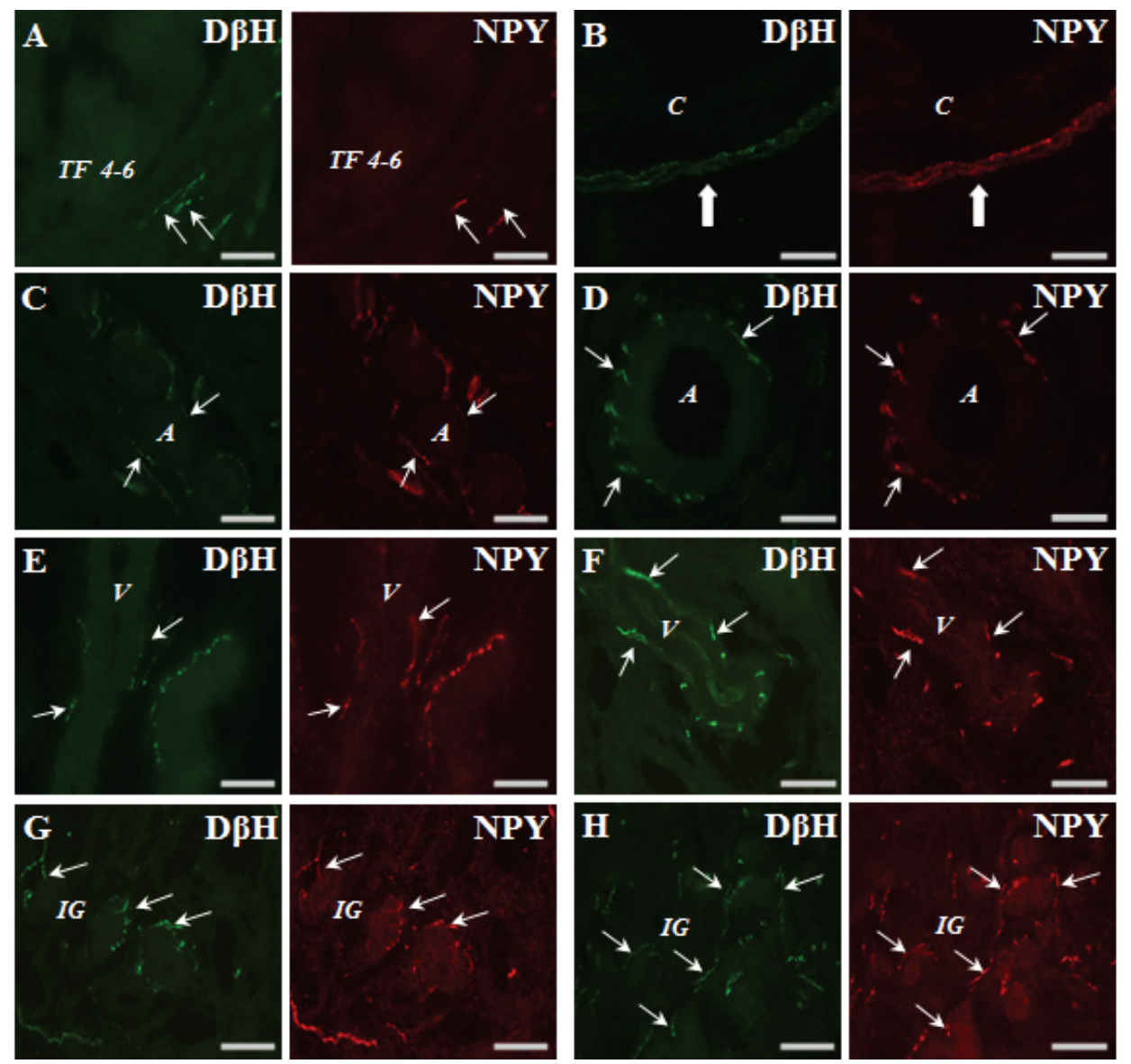

Fig. 1. Immunohistochemical localization of DBH- and/or NPYimmunoreactive (IR) nerve fibres in the ovarian cortex of the control (CON) and DXM-treated (DXM) gilts. After DXM administration numerous $\mathrm{DBH}-$ and/or NPY-IR nerve fibres are present in vicinity of the cyst (B) when compared to tertiary follicle measuring 4-6 $\mathrm{mm}$ in diameter of the control animal (A). Also in the DXM group, greater populations of $\mathrm{D} \beta \mathrm{H}-$ and/or NPY-IR nerve fibres are visible near artery (D), vein (F) and interstitial gland (H) compared to the CON group (C, E, G; respectively). Thin arrow nerve fibre, thick arrow - bunch of fibres, TF 4-6 - tertiary follicle measuring 4-6 $\mathrm{mm}$ in diameter, $C$ - cyst, $A$ - artery, $V$ - vein, IG - interstitial gland; scale bars in each picture $=25 \mu \mathrm{m}$.
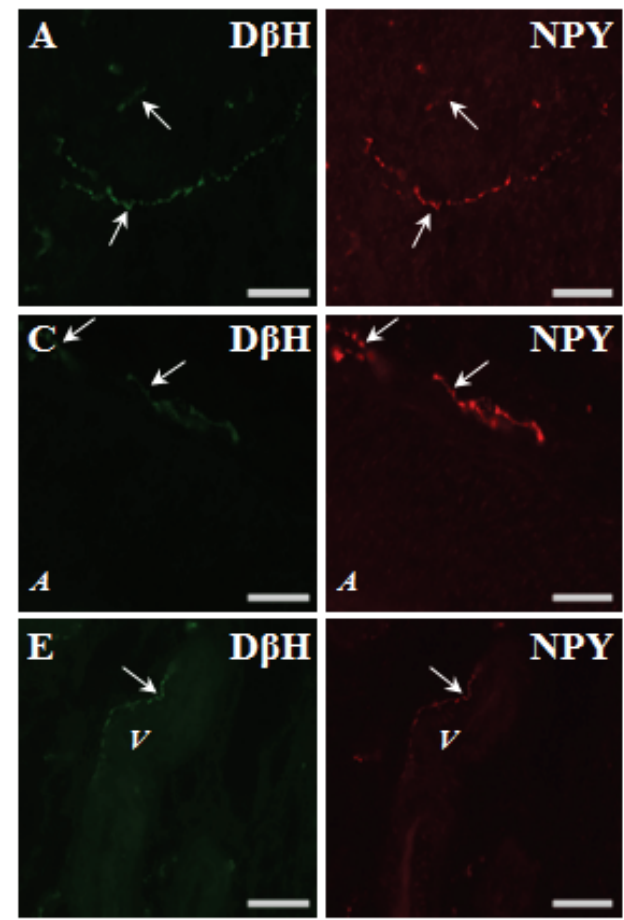
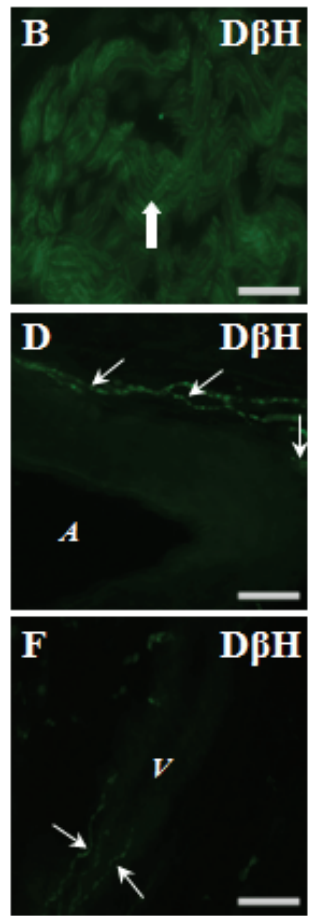
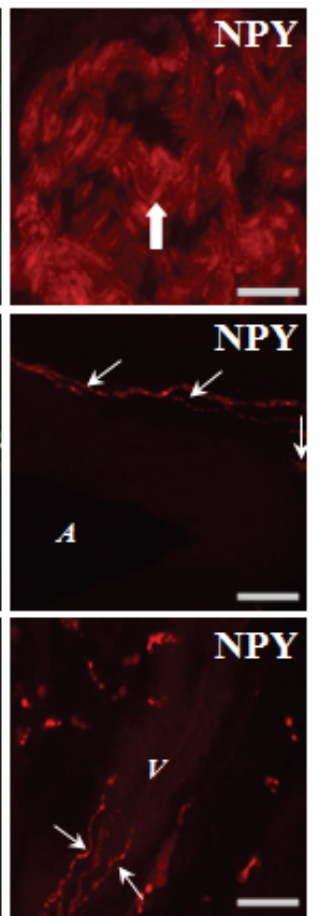

Fig. 2. Immunohistochemical localization of $\mathrm{DBH}-$ and NPYimmunoreactive (IR) nerve fibres in the ovarian medulla of the control (CON) and DXM-treated (DXM) gilts. In the ovaries of DXM-treated gilts, greater populations of $\mathrm{DBH}$ - and NPY-IR nerve fibres are visible in the area of ground plexus (B), close to the artery (D) and vein (F) compared to the CON group (A, C, E; respectively). Thin arrow nerve terminal, thick arrow bunch of fibres, $A$ - artery, $V-$ vein, scale bars in each picture $=$ $25 \mu \mathrm{m}$. 
Table 1. Mean ( \pm SEM) number of $D \beta H$ - and/or NPY-IR nerve fibres in the ovaries of gilts from the control $(C O N, n=6)$ and DXM-treated (DXM, $n=6)$ groups.

\begin{tabular}{|c|c|c|c|c|}
\hline \multirow{3}{*}{ Ovarian tissue } & \multicolumn{2}{|c|}{$\mathbf{D} \beta \mathbf{H}$} & \multicolumn{2}{|c|}{ NPY } \\
\hline & \multicolumn{4}{|c|}{ Group } \\
\hline & CON & DXM & CON & DXM \\
\hline & \multicolumn{4}{|c|}{ Cortex } \\
\hline Ground plexus & $13.3 \pm 0.9$ & $12.8 \pm 1.1$ & $11.9 \pm 1.31$ & $11.6 \pm 1.2$ \\
\hline \multicolumn{5}{|l|}{ Follicles: } \\
\hline primordial & $0.0 \pm 0.0$ & $0.0 \pm 0.0$ & $0.0 \pm 0.0$ & $0.0 \pm 0.0$ \\
\hline primary & $0.0 \pm 0.0$ & $0.0 \pm 0.0$ & $0.0 \pm 0.0$ & $0.0 \pm 0.0$ \\
\hline secondary & $1.1 \pm 0.1$ & $1.05 \pm 0.01$ & $0.0 \pm 0.0$ & $0.5 \pm 0.01$ \\
\hline \multicolumn{5}{|c|}{ tertiary with a diameter of: } \\
\hline - up to $3 \mathrm{~mm}$ & $2.5 \pm 0.5$ & $3.1 \pm 0.4$ & $2.9 \pm 0.2$ & $3.0 \pm 0.1$ \\
\hline$-4-6 \mathrm{~mm}$ & $2.8 \pm 0.4$ & l.s. & $2.7 \pm 0.1$ & l.s. \\
\hline Cysts & 1.s. & $15.1 \pm 1.4 \mathrm{~B} * * *$ & 1.s. & $13.6 \pm 1.1 \mathrm{~B} * * *$ \\
\hline Corpora lutea & $0.0 \pm 0.0$ & 1.s. & $0.0 \pm 0.0$ & 1.s. \\
\hline Arteries & $2.8 \pm 0.3$ & $12.5 \pm 0.3 * * *$ & $2.5 \pm 0.3$ & $11.6 \pm 0.15^{* * *}$ \\
\hline Veins & $1.8 \pm 0.1$ & $11.1 \pm 0.1 * * *$ & $1.9 \pm 0.2$ & $10.2 \pm 0.21 * * *$ \\
\hline \multirow[t]{2}{*}{ Interstitial gland } & $15.5 \pm 0.4$ & $22.6 \pm 0.6^{* * *}$ & $13.3 \pm 0.1$ & $21.2 \pm 0.12 * * *$ \\
\hline & \multicolumn{4}{|c|}{ Medulla } \\
\hline Ground plexus & $4.1 \pm 0.3$ & $96.8 \pm 13.1 \mathrm{~B} * * *$ & $3.6 \pm 0.4$ & $91.1 \pm 5.1 \mathrm{~B} * * *$ \\
\hline Arteries & $3.9 \pm 1.1$ & $7.9 \pm 1.2 *$ & $3.6 \pm 0.1$ & $7.7 \pm 0.5^{*}$ \\
\hline Veins & $1.01 \pm 0.01$ & $4.8 \pm 0.1 * * *$ & $1.02 \pm 0.05$ & $4.3 \pm 0.2 * * *$ \\
\hline
\end{tabular}

$* \mathrm{P}<0.05 ; * * * \mathrm{P}<0.001$ - indicate significant differences between the examined groups for the same structures and between follicles measuring 4-6 mm in diameter in the CON and cysts in the DXM group; I.s. - lack of structures, B - bunches of fibres.

Table 2. Mean ( \pm SEM) concentrations of catecholamines in the follicular fluid $[\mathrm{ng} / \mathrm{ml}]$ and in follicular wall and corpora lutea [ng/g of tissue] of gilts from the control group $(\mathrm{CON}, \mathrm{n}=6)$ as well as in the follicular and cystic fluid and wall of gilts from the DXM-treated group (DXM, $n=6)$.

\begin{tabular}{|c|c|c|c|c|c|c|c|}
\hline \multirow{2}{*}{ Group } & \multirow{2}{*}{ Structure } & \multicolumn{2}{|c|}{ Dopamine } & \multicolumn{2}{|c|}{ Noradrenaline } & \multicolumn{2}{|c|}{ Adrenaline } \\
\hline & & fluid & wall & fluid & wall & fluid & wall \\
\hline$C O N$ & Follicle size - & $0.04 \pm 0.01$ & $3.3 \pm 2.3$ & $0.2 \pm 0.02$ & $3.2 \pm 0.1$ & b.t.d & $0.4 \pm 0.4$ \\
\hline$D X M$ & $1-3 \mathrm{~mm}$ & $0.02 \pm 0.004$ & $2.4 \pm 1.02$ & $1.5 \pm 0.1^{* * *}$ & $21.1 \pm 5.6^{* * *}$ & b.t.d & $1.3 \pm 0.2$ \\
\hline$C O N$ & Follicle size - & b.t.d & $4.3 \pm 1.5$ & $3.9 \pm 0.1$ & $1.2 \pm 0.2$ & b.t.d & $0.4 \pm 0.1$ \\
\hline$D X M$ & $4-6 \mathrm{~mm}$ & 1.s. & 1.s. & 1.s. & 1.s. & 1.s. & l.s. \\
\hline$C O N$ & Corpus & - & $2.4 \pm 1.9$ & - & b.t.d & - & $0.5 \pm 0.1$ \\
\hline$D X M$ & luteum & 1.s. & l.s. & 1.s. & 1.s. & 1.s. & 1.s. \\
\hline$C O N$ & & 1.s. & 1.s. & 1.s. & l.s. & $1 . \mathrm{s}$ & 1.s. \\
\hline$D X M$ & Cysts & b.t.d & $16.7 \pm 2.5^{* * *}$ & $0.004 \pm 0.001^{* * *}$ & $129.2 \pm 3.2^{* * *}$ & b.t.d & $6.2 \pm 0.6^{* * *}$ \\
\hline
\end{tabular}

${ }^{* * *} \mathrm{P}<0.001$ - indicates significant differences between the examined groups for the same structures and between follicles measuring 4-6 mm in diameter in the CON and cysts in the DXM group; I.s. - lack of structure; b.t.d. - value below the threshold of detection. 


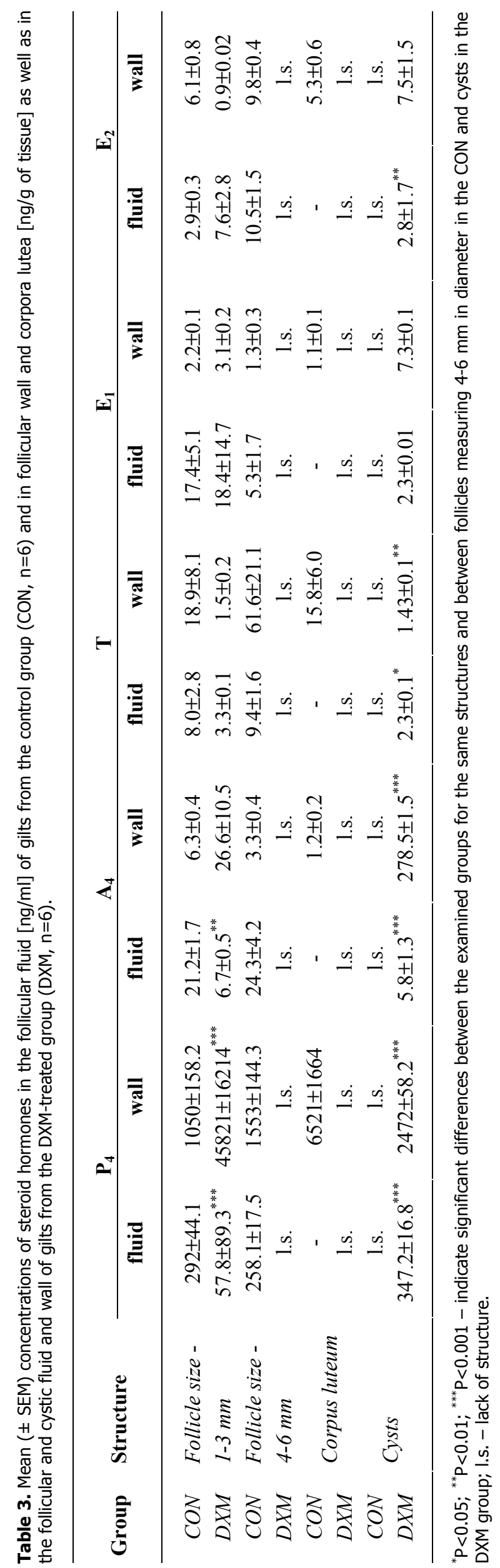


Content of steroid hormones in the cystic and follicular fluid

After DXM administration, the content of $\mathrm{P}_{4}$ in the cystic fluid was higher $(\mathrm{P}<0.001)$ than in medium follicles of the CON group. The levels of $\mathrm{A}_{4}(\mathrm{P}<0.001)$, $\mathrm{T}(\mathrm{P}<0.05)$ and $\mathrm{E}_{2}(\mathrm{P}<0.01)$ in the cystic fluid as well as $\mathrm{P}_{4}(\mathrm{P}<0.001)$ and $\mathrm{A}_{4}(\mathrm{P}<0.01)$ in the fluid from small follicles of the gilts receiving DXM, were lower than in the CON group. In turn, the contents of $E_{1}$ in the cystic fluid and $T, E_{1}$ and $E_{2}$ in the fluid from small follicles varied insignificantly between the examined groups (Table 3).

Content of steroid hormones in the cystic and follicular wall

DXM injections caused an increase $(\mathrm{P}<0.001)$ in the concentrations of $\mathrm{P}_{4}$ and $\mathrm{A}_{4}$ in the wall of cysts, and $\mathrm{P}_{4}$ in the wall of small follicles. Comparing to the CON group, the concentration of $\mathrm{T}$ declined $(\mathrm{P}<0.01)$ in the cystic wall. No significant differences were noted in the $\mathrm{E}_{1}$ and $\mathrm{E}_{2}$ contents in the cystic wall and in the $\mathrm{A}_{4}, \mathrm{~T}, \mathrm{E}_{1}$ and $E_{2}$ concentrations in the wall of small follicles between both the CON and DXM groups (Table 3).

\section{Discussion}

The present study shows that in the porcine cystic ovaries, induced by DXM administration on days 7-21 of the estrous cycle, the number of noradrenergic nerve fibres was increased and accompanied by alterations in the content of catecholamines and steroid hormones in ovarian structures.

We have found that the number of $\mathrm{D} \beta \mathrm{H}-$ and/or NPY-IR nerve fibres increased in the cystic-changed ovaries. This is in agreement with previous studies performed on the cystic ovaries of women (Nakamura 1990, Heider et al. 2001) and gilts receiving DXM from follicular phase of the estrous cycle (Jana et al. 2005). It is difficult to indicate the mechanism(s) underlying the increase of the number of noradrenergic nerve fibres in the cystic ovaries found in our study. We suggest that this situation may be a consequence of a local ovarian mechanism that results in neuronal plasticity. Thus, the higher density of nerve fibres may be referred to the elevated production of NGF, which plays a crucial role in development, survival and differentiation of sympathetic and sensory neurons and in the regulation of axon and dendrite growth (Huang and Reichardt 2001). This assumption is based on the findings that the contents of
NGF and its receptor (p75) were augmented in rat EV-induced polycystic ovaries (Lara et al. 2000) and porcine cystic ovaries evoked by DXM (Jana et al., unpub. data). In addition, in rats this was accompanied by an increase in both the level of tyrosine hydroxylase (TH) mRNA expression in the celiac ganglion and the number of ovarian noradrenergic nerve endings (Lara et al. 2000). Thus, changes in the chemical coding of neurons may resulted from direct effects of steroid hormones on these cells, as it has been shown that estrogen receptors (ERs) are expressed by ovarian neurons of the caudal mesenteric ganglion (CaMG) (Koszykowska et al. 2011a) and sympathetic chain ganglia ( $\mathrm{SChG}$ ) (Koszykowska et al. 2011b) in adult gilts. In turn, androgen or progesterone receptors were localized in the neurons in the dorsal root ganglia (DRG) of male (Keast and Gleeson 1998) and female (Chan et al. 2000) rats, respectively. Furthermore, the long-term $\mathrm{E}_{2}$ treatment lead to the decrease in the number of both noradrenergic and ERs expressing ovarian neurons in the porcine CaMG and SChG (Koszykowska et al. 2011a,b). It is worth adding that in the gilts, from which the cystic ovaries were collected for the present study, the peripheral blood levels of sex steroids increased (Jana et al., unpub. data). It is possible that the increase in the numbers of D $\beta \mathrm{H}$ - and/or NPY-IR nerve fibres studied the cystic ovaries, can be also a consequence of the DXM administration. This assumption is supported by studies showing that in rats DXM lead to the increase in the density of TH-IR nerve fibres in the uterus (Bianchimano et al. 2007) and the expression of NPY mRNA and protein in the isolated islets of Langerhans (Jamal et al. 1991) as well as that the part of neurons in the lumbar DRG possesses nuclear glucocorticoid receptors (DeLeón et al. 1994). Changes in the pattern of noradrenergic innervation of cystic ovaries, revealed in the present study, referred only to the density of $\mathrm{D} \beta \mathrm{H}-$ and/or NPY-IR nerve fibres surrounding particular ovarian structures, but not their distribution. Thus, the increase in the number of noradrenergic nerve fibres was found especially around the cysts, interstitial glands, blood vessels and in the area of ground plexus in the medulla. These observations correspond to our earlier study (Jana et al. 2005), in which cystic changes in porcine ovaries were induced by DXM injections starting at follicular phase of the cycle. However, in the present study the number of noradrenergic nerve fibres around cysts was significantly lower, whereas it was significantly higher in the vicinity of the interstitial gland and cortical veins 
when compared with the mentioned study (Jana et al. 2005).

An augmentation in the density of the D $\beta \mathrm{H}$ and/or NPY-IR nerve fibres found in the present study in the vicinity of the cysts was accompanied by an increase in the level of NA and AA in the wall of these structures, which was earlier revealed after DXM administration at follicular phase of the cycle; however, they significantly higher than those observed in our previous study (Jana et al. 2005).

Interestingly, the whole concentration of NA in the cystic fluid was significantly lower, when as compared to earlier findings, while the increase in the NA content in the wall of small tertiary follicles was in line with our previous data (Jana et al. 2005). Moreover, an increase in the level of DA (in the cyst wall) as well as of NA (in the fluid of small tertiary follicles) was found in the present study when compared to results obtained previously (Jana et al. 2005). A rise in the NA concentration was also reported in rat cystic ovaries (Barria et al. 1993, Lara et al. 1993) and in the cystic fluid in cows (Paredes et al. 2011). We suggest that the increase in the content of catecholamines found in the present study could be a consequence of intensified synthesis and release of these substances. A high NA content in the cysts may also result from an enhanced release of catecholamine from numerous noradrenergic fibres supplying the cysts, which was suggested earlier by Lara et al. (1993). Moreover, such high concentration of NA in the wall and/or fluid of cysts and follicles may resulted from the ability of steroidogenic cells to take up NA, store it, and upon depolarization, release it, which was presented in ovarian granulosa cells (Greiner et al. 2008, Saller et al. 2012). An additional source of NA in the cysts and follicles may be adrenal medulla (for a review see Stener-Victorin et al. 2005). In turn, the higher DA content in the cystic wall may be caused by the increased inflow of this catecholamine into the ovary with blood stream, which may be judged from the study of Rothschild et al. (1984), who observed an increase in the plasma level of free DA in humans receiving DXM.

The present study also revealed changes in the concentration of steroid hormones in the ovarian structures of DXM-treated gilts. We noticed a higher content of $\mathrm{P}_{4}$ in the cysts (wall, fluid), which is in line with our earlier study, in which cystic changes in gilt ovaries were induced by DXM administrated at follicular phase of the cycle (Jana et al. 2005). The content of $\mathrm{P}_{4}$ increased also in the theca interna layer of the follicles in polycystic ovaries of women (Gilling-Smith et al. 1994). The elevated content of $\mathrm{P}_{4}$ in the wall of cysts and small follicles, found in our study, was accompanied by an increase in the contents of catecholamines and levels of

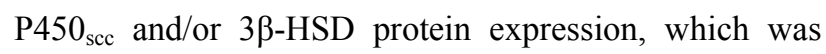
earlier reported by Kozłowska et al. (2009). The interrelationship can be explained by stimulatory effect of NA on expression and activity of P450 $0_{\text {scc }}$ and $3 \beta$-HSD (Miszkiel and Kotwica 2001, Kotwica et al. 2002). It has also been reported that DA and NA augmented $\mathrm{P}_{4}$ production and secretion from bovine (Kotwica et al. 1996) and porcine (Wiesak et al. 1991) luteal cells. It is also possible that the increase in the $\mathrm{P}_{4}$ content in the cysts and follicles, observed in the present study, could be the result of NPY effect, as reported previously by Baranowska et al. (1999). We have also found that the contents of $\mathrm{A}_{4}$ in cystic fluid, $\mathrm{T}$ in cystic wall and fluid, and $\mathrm{A}_{4}$ in the fluid from small tertiary follicles decreased after DXM injections from the middle luteal phase of the cycle. Similar phenomenon was reported earlier in the porcine cystic ovaries formed by DXM injections starting at follicular phase of the cycle (Jana et al. 2005). Moreover, a similar decrease in the concentration of $\mathrm{T}$ was previously observed in the porcine cysts (Scharfe et al. 1994). In turn, Paredes et al. (2011) revealed an increase in basal and isoproteneol ( $\beta$-receptor agonist)and hCG-stimulated release of $\mathrm{T}$ from bovine cystic wall. The present study showed also that the content of $\mathrm{A}_{4}$ in the cystic wall was significantly higher, while it was markedly lower after induction of cystic changes at follicular phase of the cycle (Jana et al. 2005) as compared to the control groups. It is possible that this increase in the $\mathrm{A}_{4}$ content in cystic wall (present study), could be caused by higher conversion rate of $\mathrm{P}_{4}$ to $\mathrm{A}_{4}$ (Gilling-Smith et al. 1994). Moreover, Jakimiuk et al. (2001) showed a rise in the expression of $17 \alpha$-hydroxylase/C (17-20) lyase mRNA in the theca interna layer of follicles $(3-7 \mathrm{~mm}$ in diameter) from polycystic ovaries of women. We suppose that the increase in the content of $\mathrm{A}_{4}$ found by us in the ovarian structures of DXM-treated gilts, may also be caused by $\mathrm{NA}$, as it was presented in rat cystic ovaries (Barria et al. 1993). In the present study a reduction in the $E_{2}$ content in the cystic fluid was demonstrated, similarly as after formation of cystic condition by DXM administrated at follicular phase of the cycle (Jana et al. 2005). However, we were not able to find significant changes in the contents of $E_{2}$ in the cystic wall and $E_{1}$ in the cystic wall and fluid, while the amounts of these steroid were 
significantly lower in the treated with DXM gilts from follicular phase of the cycle (Jana et al. 2005).

In our previous (Kozłowska et al. 2009) and in the present studies we have revealed that the morphology (macroscopic changes, the noradrenergic innervation pattern) and steroidogenic activity of the porcine cystic ovaries induced by DXM treatment from middle luteal phase are in part different from those found after DXM administration started from follicular phase of the cycle (Jana et al. 2005). Most probably, these differences may result from other phase of the estrous cycle (different stage of follicular development and hormonal status), in which the injections of DXM started. This supposition is supported by previous studies indicating that application of ACTH or glucocorticoids in pigs before or after the time of ovulatory follicle selection resulted in differential macroscopic and steroid hormone changes of cystic ovaries (Gee et al. 1991). Thus is additionally supported by findings showing that the contents of catecholamines changed distinctly in porcine ovaries in the course of the estrous cycle (Lakomy 1987) as well as that the density of noradrenergic innervation of gilt follicles dependent on their developmental stage (Majewski 1997). Considering the partly different morphological and functional changes found between the cystic ovaries, induced by DXM from the middle luteal (present study, Kozłowska et al. 2009) and follicular (Jana et al. 2005) phase of the estrous cycle, we speculate that differential cystic changes occurring in natural conditions may result, at least partly, from the phase of the cycle, in which the activation of the HPA axis and sympathetic innervation took place. However, this assumption must be further elucidated in detail.

In conclusion, data of the present study clearly show that in the porcine cystic ovaries, formed after DXM injections from middle luteal phase of the estrous cycle, both density of noradrenergic nerve fibres as well as the concentration of catecholamines have increased. It was simultaneously accompanied by changes in the content of steroid hormones. Our study is a further confirmation that morphological and functional changes of cystic ovaries are partly dependent on phase of the estrous cycle in which the induction of the ovarian cysts was initiated.

\section{Conflict of Interest}

There is no conflict of interest.

\section{Acknowledgements}

This work was supported by grant no. 3PO6K00722 from the State Committee for Scientific Research in Poland and funds of the Polish Academy of Sciences.

\section{References}

BALEN AH, JACOBS HS: A prospective study comparing unilateral and bilateral laparoscopy ovarian diathermy in women with the polycystic ovary syndrome. Fertil Sterl 62: 921-924, 1994.

BARANOWSKA B, CHMIELOWSKA M, RADZIKOWSKA M, BOROWIEC M, ROGUSKI K, WASILEWSKADZIUBINSKA E: Effects of neuropeptide Y (NPY), galanin and vasoactive intestinal peptide (VIP) on pituitary hormone release and ovarian steroidogenesis. Neuro Endocrinol Lett 20: 385-389, 1999.

BARBONI B, MARTELLI A, BERARDINELLI P, RUSSO V, TURRIANI M, BERNABÒ N, LUCIDI P, MATTIOLI M: Ovarian follicle vascularization in fasted pig. Theriogenology 62: 943-957, 2004.

BARRIA A, LEYTON V, OJEDA SR, LARA HE: Ovarian steroidal response to gonadotropins and beta-adrenergic stimulation enhanced in polycystic ovary syndrome: role of sympathetic innervation. Endocrinology 133: 2696-2703, 1993.

BIANCHIMANO P, FRÍAS AI, RICHERI A, BRAUER MM: Effects of dexamethasone on estrogen- and pregnancyinduced plasticity in rat uterine sympathetic nerves. Cell Tissue Res 330: 413-425, 2007.

CECH S, DOLEZEL R: Treatment of ovarian cysts in sows - a field trial. Vet Med 52: 413-418, 2007.

CHAN JR, RODRIGUEZ-WAITKUS PM, NG BK, LIANG P, GLASER M: Progesterone synthesized by Schwann cells during myelin formation regulates neuronal gene expression. Mol Biol Cell 11: 2283-2295, 2000.

DELEÓN M, COVEÑAS R, CHADI G, NARVÁEZ JA, FUXE K, CINTRA A: Subpopulations of primary sensory neurons show coexistence of neuropeptides and glucocorticoid receptors in the rat spinal and trigeminal ganglia. Brain Res 636: 338-342, 1994.

DZIADKOWIEC J, DANILCZUK H, REMBIESA R: Biosynthesis of progesterone in rat placenta. Endokrynol Pol 33: 201-207, 1982a. 
DZIADKOWIEC J, WARCHOŁ A, REMBIESA R: Biosynthesis of estrogens in pregnant rats. Endokrynol Pol 33: 4-6, 1982b.

FIEDLER J, JARA P, LUZA S, DORFMAN M, GROUSELLE D, RAGE F, LARA HE, ARANCIBIA S: Cold stress induces metabolic activation of thyrotrophin-releasing hormone-synthesising neurones in the magnocellular division of the hypothalamic paraventricular nucleus and concomitantly changes ovarian sympathetic activity parameters. J Neuroendocrinol 18: 367-376, 2006.

FRAUTSCHY SA, LIPTRAP RM: Anovulation and plasma hormone concentrations after administration of dexamethasone during the middle of the luteal phase in sows undergoing estrous cycles. Am J Vet Res 49: 1270-1275, 1988.

GEE CM, GEISSINGER HD, LIPTRAP RM: Morphometric and steroid hormone changes associated with experimental anovulatory follicles in the sow. Can J Vet Res 55: 206-211, 1991.

GILLING-SMITH C, WILLIS DS, BEARD RW, FRANKS S: Hypersecretion of androstenedione by isolated thecal cells from polycystic ovaries. J Clin Endocrinol Metab 79: 1158-1165, 1994.

GREINER M, PAREDES A, REY-ARES V, SALLER S, MAYERHOFER A, LARA HE: Catecholamine uptake, storage, and regulated release by ovarian granulosa cells. Endocrinology 149: 4988-4996, 2008.

HEIDER U, PEDAL I, SPANEL-BOROWSKI K: Increase in nerve fibres and loss of mast cells in polycystic and postmenopausal ovaries. Fertil Steril 75: 1141-1147, 2001.

HOTCHKISS J, ATKINSON LE, KNOBIL E: Time course of serum estrogen and luteinizing hormone (LH) concentration during the menstrual cycle of the rhesus monkey. Endocrinology 89: 117-183, 1971.

HUANG EJ, REICHARDT LF: Neurotrophins: roles in neuronal development and function. Annu Rev Neurosci 24: 677-736, 2001.

JAKIMIUK AJ, WEITSMAN SR, NAVAB A, MAGOFFIN DA: Luteinizing hormone receptor, steroidogenesis acute regulatory protein, and steroidogenic enzyme messenger ribonucleic acids are overexpressed in thecal and granulosa cells from polycystic ovaries. J Clin Endocrinol Metab 86: 1318-1323, 2001.

JAMAL H, JONES PM, BYRNE J, SUDA K, GHATEI MA, KANSE SM, BLOOM SR: Peptide contents of neuropeptide $\mathrm{Y}$, vasoactive intestinal polypeptide, and beta-calcitonin gene-related peptide and their messenger ribonucleic acids after dexamethasone treatment in the isolated rat islets of Langerhans. Endocrinology 129: 3372-3380, 1991.

JANA B, DZIENIS A, ROGOZIŃSKA A, PISKUŁA M, JEDLIŃSKA-KRAKOWSKA M, WOJTKIEWICZ J, MAJEWSKI M: Dexamethasone-induced changes in sympathetic innervation of porcine ovaries and their steroidogenic activity. $J$ Reprod Dev 51: 715-725, 2005.

JANA B, DZIENIS A, WOJTKIEWICZ J, KACZMAREK M, MAJEWSKI M: Surgical denervation of ovaries in the gilts during the middle luteal phase of the estrous cycle changes morphology and steroidogenic activity of gonads. Acta Vet Hung 55: 107-122, 2007.

KEAST JR, GLEESON RJ: Androgen receptor immunoreactivity is present in primary sensory neurons of male rats. Neuroreport 21: 4137-4140, 1998.

KESLER DJ, GARVERICK HA: Ovarian cysts in dairy cattle: a review. J Anim Sci 55: 1147-1159, 1982.

KOTWICA J, WILLIAMS GL: Relationship of plasma testosterone concentrations to pituitary-ovarian hormone secretion during the bovine estrous cycle and the effects of testosterone propionate administration during luteal regression. Biol Reprod 27: 790-801, 1982.

KOTWICA J, SKARZYNSKI D, BOGACKI M, JAROSZEWSKI J: Role of dopamine in the secretory function of corpus luteum in cattle. $J$ Physiol Pharmacol 47: 477-486, 1996.

KOTWICA J, BOGACKI M, RĘKAWIECKI R: Neural regulation of the bovine corpus luteum. Domest Anim Endocrinol 23: 299-308, 2002.

KOSZYKOWSKA M, CALKA J, SZWAJCA P, JANA B: Long-term estradiol-17 $\beta$ administration decreases the number of neurons in the caudal mesenteric ganglion innervating the ovary in sexually mature gilts. $J$ Reprod Dev 57: 62-71, 2011a.

KOSZYKOWSKA M, CAŁKA J, GAŃKO M, JANA B: Long-term estradiol-17 $\beta$ administration reduces population of neurons in the sympathetic chain ganglia supplying the ovary in adult gilts. Exp Mol Pathol 91: 353-361, $2011 b$. 
KOZŁOWSKA A, MAJEWSKI M, JANA B: Expression of steroidogenic enzymes in porcine polycystic ovaries. Folia Histochem Cytobiol 2: 1-8, 2009.

ŁAKOMY M: Adrenergic and cholinergic innervation of female reproductive organs in pig during the estrous cycle, pregnancy and lactation (in Polish). Zesz Probl Postępów Nauk Rol 339: 89-104, 1987.

ŁAKOMY M, SZATKOWSKA C, CHODKOWSKA D: Changes of noradrenaline content in the adrenergic nerves of the pig ovaries different periods of the oestrous cycle. Ann Anat 166: 149-155, 1988.

LARA HE, FERRUZ JL, LUZA S, BUSTAMANTE DA, BORGES Y, OJEDA SR: Activation of ovarian sympathetic nerves in polycystic ovary syndrome. Endocrinology 133: 2690-2695, 1993.

LARA HE, DISSEN GA, LEYTON V, PAREDES A, FUENZALIDA JL, FIEDLER JL, OJEDA SR: An increase intraovarian synthesis on nerve growth factor and its low affinity receptor is a principal component of steroidinduced polycystic ovary in rat. Endocrinology 141: 1059-1072, 2000.

LI XF, BOWE JE, LIGHTMAN SL, O'BYRNE KT: Role of corticotropin-releasing factor receptor-2 in stress-induced suppression of pulsatile luteinizing hormone secretion in the rat. Endocrinology 146: 318-322, 2005.

MADEJ A, MWANZA AM, KINDAHL H, EINARSSON S: Effect of ACTH and CRH on plasma levels of cortisol and prostaglandin F2alpha metabolite in cycling gilts and castrated boars. Acta Vet Scand 46: 249-256, 2005.

MAJEWSKI M: Afferent and efferent innervation of the porcine ovary-sources of origin and chemical coding (in Polish). Acta Acad Agric Tech Olst, Veterinaria, supplementum B 24: 3-125, 1997.

MANNI L, HOLMANG A, LUNDEBERG T, ALOE L, STENER-VICTORIN E: Ovarian expression of alpha (1)- and beta (2)- adrenoceptors and $\mathrm{p} 75$ neurotrophin receptors in rats with steroid-induced polycystic ovaries. Auton Neurosci 118: 79-87, 2005.

MISZKIEL G, KOTWICA J: Mechanism of action of noradrenaline on secretion of progesterone and oxytocin by the bovine corpus luteum in vitro. Acta Vet Hung 49: 39-51, 2001.

MORALES-LEDESMA L, LINARES R, ROSAS G, MORÁN C, CHAVIRA R, CÁRDENAS M, DOMÍNGUEZ R: Unilateral sectioning of the superior ovarian nerve of rats with polycystic ovarian syndrome restores ovulation in the innervated ovary. Reprod Biol Endocrinol 8: 99, 2010.

MORÁN C, MORALES L, RAZO RS, APOLONIO J, QUIROZ U, CHAVIRA R, DOMINIGUEZ R: Effects of sensorial denervation induced by capsaicin injection at birth or on day three of life, on puberty, induced ovulation and pregnency. Life Sci 73: 2113-2125, 2003.

NAKAMURA Y: Treatment of polycystic ovary syndrome: an overview. Horm Res 33: 31, 1990.

NALBANDOV V: Anatomic and endocrine causes of sterility in female swine. Fertil Steril 3: 100-120, 1952.

PAREDES AH, SALVETTI NR, DIAZ AE, DALLARD BE, ORTEGA HH, LARA HE: Sympathetic nerve activity in normal and cystic follicles from isolated bovine ovary: local effect of beta-adrenergic stimulation on steroid secretion. Reprod Biol Endocrinol 9: 66, 2011.

PETER AT: An update on cystic ovarian degeneration in cattle. Reprod Domest Anim 39: 1-7, 2004.

ROTHSCHILD AJ, LANGLAIS PJ, SCHATZBERG AF, WALSH FX, COLE JO, BIRD ED: Dexamethasone increases plasma free dopamine in man. $J$ Psychiatr Res 18: 217-223, 1984.

SALLER S, MERZ-LANGE J, RAFFAEL S, HECHT S, PAVLIK R, THALER C, BERG D, BERG U, KUNZ L, MAYERHOFER A: Norepinephrine, active norepinephrine transporter, and norepinephrine-metabolism are involved in the generation of reactive oxygen species in human ovarian granulosa cells. Endocrinology 153: 1472-1483, 2012.

SCHARFE S, SCHNURRBUSH U, GOTTSCHALK J: Concentrations of 17 beta-estradiol, testosterone and progesterone in ovarian cyst fluid and intact ovarian follicles of swine. Tierärztl Prax 22: 245-251, 1994.

SILVIA WJ, HATLER TB, NUGENT AM, LARANJA DA FONSECA LF: Ovarian follicular cysts in dairy cows: an abnormality in folliculogenesis. Domest Anim Endocrinol 23: 167-177, 2002.

SKIPOR J, WASOWSKA B, PICARD S, THIÉRY JC: Access of dopamine to the median eminence and brain throughout local vascular pathways in sheep. Reprod Biol 4: 91-106, 2004.

STENER-VICTORIN E, PLOJ K, LARSSON BM, HOLMÄNG A: Rats with steroid-induced polycystic ovaries develop hypertension and increased sympathetic nervous system activity. Reprod Biol Endocrinol 3: 44, 2005. 
SZAFRAŃSKA B, ZIECIK A, OKRASA S: Primary antisera against selected steroids or proteins and secondary antisera against gamma-globulins-an available tool for studies of reproductive processes. Reprod Biol 2: 187204, 2002.

SZULAŃCZYK-MENCEL K, RZASA A, BIELAS W: Relationships between ovarian cysts and morphological and hormonal state of ovarian cortex in sows. Anim Reprod Sci 121: 273-278, 2010.

TSANG PC, WALTON JS, HANSEL W: Oxytocin-specyfic RNA, oxytocin and progesterone concentrations in corpora lutea of heifers treated with oxytocin. J Reprod Fertil 89: 77-84, 1990.

TURNER AI, CANNY BJ, HOBBS RJ, BOND JD, CLARKE IJ, TILBROOK AJ: Influence of sex and gonadal status of sheep on cortisol secretion in response to ACTH and on cortisol and LH secretion in response to stress: importance of different stressors. $J$ Endocrinol 173: 113-122, 2002.

WIESAK T, HUNTER MG, PRZALA J: Catecholamines regulate the steroidogenesis by luteal cells from early pregnant pig. Endoc Regul 25: 193-197, 1991.

WULFF C, WILSON H, WIEGAND SJ, RUDGE JS, FRASER HM: Prevention of thecal angiogenesis, antral follicular growth, and ovulation in the primate by treatment with vascular endothelial growth factor trap R1R2. Endocrinology 143: 2797-2807, 2002. 